\title{
Attention-Deficit and Hyperactivity Disorder: A Disorder or a Fraud?
}

\author{
Rony Chaaya ${ }^{1} \&$ Diala El Khoury ${ }^{2}$ \\ ${ }^{1}$ Department of Health Sciences, Faculty of Medicine, Lithuanian University of Health Sciences, Kaunas, \\ Lithuania \\ ${ }^{2}$ Department of Sciences, Faculty of Natural and Applied Sciences, Notre Dame University, Louaize, Lebanon \\ Correspondence: Diala El Khoury, Department of Sciences, Faculty of Natural and Applied Sciences, Notre Dame \\ University, Louaize, Lebanon. E-mail: delkhoury@ndu.edu.lb
}

Received: February 18, 2019 Accepted: April 2, 2019 Online Published: April 8, 2019

doi:10.5539/gjhs.v11n5p100 URL: https://doi.org/10.5539/gjhs.v11n5p100

\begin{abstract}
Attention Deficit Hyperactivity Disorder is a psychiatric and behavioral disorder marked by chronic inattention and/or hyperactivity-impulsivity that interferes with functioning or development. This disorder is caused by many dysfunctions in the brain especially in the prefrontal cortex. To date, numerous studies have attempted to unravel the biological pathways behind ADHD. Many environmental risk factors have been identified including lead exposure and prenatal alcohol and tobacco exposure. Specific mutations in genes affecting dopamine and norepinephrine release are also under investigation. Moreover, around three thousand papers have been published showing that ADHD is due to an abnormal dopamine and norepinephrine neurotransmitters secretion in the prefrontal cortex (PFC). This paper aims to provide an updated review of the biological causes of ADHD with an unprecedented focus on different cellular pathways involving catecholamine secretion in the prefrontal cortex. A well rounded and comprehensive review of the etiology of ADHD would prevent its misdiagnosis by health professionals and consequently restrict its malpractice by the use of unnecessary treatments and medications. The ADHD controversy still remains: a disorder or a fraud?
\end{abstract}

Keywords: attention deficit hyperactivity disorder, dopamine, fraud, hyperactivity, impulsivity, inattention, misdiagnosis, norepinephrine, prefrontal cortex

\section{Introduction}

ADHD is a behavioral condition characterized by a short attention span; it can be accompanied by hyperactivity (Barkley, 1981). The Diagnostic and Statistical Manual DSM-5 of the American Association describes 3 basic types of ADHD: inattentive; hyperactive-impulsive; and combined. The percentage of children diagnosed with ADHD increased over the last few years by $10 \%$, especially in the United States, meanwhile other studies suggest that the worldwide prevalence of ADHD is between $8 \%$ and $12 \%$ (Pediatrics, 2000). This disorder is mostly diagnosed in school-aged children between 5 and 17 years of age, and its prevalence is 3 to 5 times more common in boys than girls. While boys tend to be more hyperactive and impulsive, girls are inclined to be more inattentive (Gaub \& Carlson, 1997). ADHD in children may lead to academic-social difficulties and challenges: their inattentive behavior prevents them from receiving and processing information properly and following instructions becomes challenging due their impulsive conduct (Association, 1980). The disorder has different symptoms and causes which are rooted in a neuro-chemical dysfunction in the brain.

Research about ADHD in children has exponentially grown during the last decade. Around three thousand articles can be retrieved from scientific databases using "ADHD" and "etiology" as keywords; and the latest review on the pathophysiology, etiology, and treatment of ADHD was published in 2014 (Sharma \& Couture, 2014).

To date, most research has focused on the biological pathway of ADHD involving the pathophysiology of catecholamine secretion in the brain (A. F. Arnsten, 2007). However, there were no recent reports with an updated review concerning the other biological aspects of ADHD such as the pathophysiology of dopamine secretion and the role of signaling pathways involving Guanylyl Cyclase-C receptor and the Akt-mTOR signaling pathway.

Furthermore, opposing viewpoints appear between studies that dismiss ADHD as a fictitious disorder while others approve ADHD's classification as a legitimate disorder caused by dysfunctions in the brain and/or environmental factors. ADHD is thus sometimes considered to be a myth rather than a disorder (Kagan, 2009). This review paper will expand on the different types of ADHD, delineate its evolution from 1902 until recent times, and attempt to 
reach a consensus regarding the legitimacy of ADHD.

\section{Method}

We used three databases: PubMed, Science Direct and Google Scholar. Search restrictions were based on the English language, year of publication between 2003 and 2019, type of publication set to journal, and human and rodent experimental models. We excluded all the articles and reviews that researched ADHD and Autism together in the same study.

No review work was found to determine ADHD as fake or a real biological disorder at the same time. The only review paper found on PubMed that linked controversy of the disorder involved only one epidemiological study (Pena \& Montiel-Nava, 2003) and did not tackle all the biological aspects of ADHD.

The selected reports detailing cellular pathways were collected in an EndNote library and further checked for full screen of titles and abstracts. We intially started by analyzing reports defining ADHD in children and elaborating its symptoms, causes and most importantly its biological pathways. Moreover, we examined papers involving different treatments for ADHD and found it interesting to include new treatment approaches away from pharmaceutical drug use, such as physical exercise. Finally, we connected all pertinent information in an attempt to bring about an answer to the title of our paper.

\section{Results}

\subsection{What is ADHD?}

Attention Deficit Hyperactivity Disorder abbreviated as ADHD is a brain disorder marked by an inability to maintain attention and/or hyperactivity-impulsivity that disrupt functioning or development (Biederman, 1998). Inattention occurs when children have difficulty in maintaining focus. They wander off during tasks, lack persistence and determination, and are disorganized. Hyperactivity is observed by a frequent restlessness when children move about constantly especially in situations in which it is not appropriate. Moreover, hyperactivity is also characterized by excessive fidgets, taps or talks, and extreme restlessness. On the other hand, impulsivity is when children produce rapid actions without even thinking about them and that may pose high potential for harm. They may excessively interrupt others making them socially intrusive. In addition to that, children may jump to important decisions without considering the long-term consequences (Association, 1980).

The disorder was first mentioned in 1902 by a British pediatrician, Sir George Still, who found that some children could not control their behavior the way a normal child could, but they were still intelligent. This behavior was described as "an abnormal defect of moral control in children" (Still, 1902). In 1952, the "Diagnostic and Statistical Manual of Mental Disorders" (DSM) issued for the first time (Association, 1952) summarized a list of all universally recognized mental disorders with their causes, risk factors, and treatments; among which ADHD was absent. It was not until 16 years later that the second DSM included hyperactivity impulse disorder in the list (Association, 1968). The name of the disorder changed from "hyperkinetic impulse disorder" to "Attention Deficit Disorder" or ADD in the third edition of the DSM (Association, 1980). At that time, the "H" was not there because psychologists believed that hyperactivity was not a common symptom of the disorder, hence they created two subtypes of ADD: ADD with hyperactivity and ADD without hyperactivity (Barkley, 1981). ADHD was still known as ADD until 1987 when they released a revised version of the DSM-III: scientists removed the hyperactivity distinction and changed the name into Attention Deficit Hyperactivity (Association, 2000). They believed that the disorder had no subtypes and combined the three distinctive symptoms of inattentiveness, impulsivity, and hyperactivity. Finally, the APA released the fourth edition of DSM in 2000 by recognizing that ADHD has three subtypes: combined ADHD, predominantly inattentive type of ADHD, and predominantly hyperactive-impulsive type of ADHD (Association, 2000).

\subsection{Symptoms of $A D H D$}

ADHD subtypes can be distinguished by inattention or hyperactivity/impulsivity. While some children with the disorder experience problems with one of these behaviors, others experience both in what is termed the combined type of ADHD. Nonetheless, taking into consideration the age of the child and their surrounding, a small degree of inattention, uncoordinated motor activity and careless impulsivity may seem relatively normal. The difference from ADHD children lies in the severity and frequency of these behaviors. The World Health Organization (WHO) initially reported that children with inattention problems often have difficulties in sustaining attention during tasks or play, including conversations, lectures or lengthy readings. They often fail to keep close attention to details and commit careless mistakes in their responsibilities or during other mundane activities. They often have difficulties following instructions and fail to finish schoolwork on time; they are sometimes able to start tasks but quickly lose focus and get easily sidetracked. On the other hand, organizing tasks and activities are challenging for them: they 
do not know what to do in sequence and lose things necessary for the completion of the tasks or activities. Inattention is diagnosed when a child has at least 6 of the previous symptoms of inattention that must have persisted for at least 6 months (Association, 2013). Children with ADHD get easily distracted by external stimuli because of a lack of sensory filtration at the level of the caudate nucleus; nerve cells in the brain that process all sensory input before directing it to conscious awareness. This nucleus acts as a gatekeeper that allows only relevant stimuli to reach conscious awareness (Barkley, 1997). Gupta (2005) showed that children with ADHD have a relatively smaller right-sided caudate nucleus than normal children; thus every stimulus that arrives to it is brought to conscious awareness without proper processing; that is why ADHD patients are easily distracted (Gupta, 2005).

Who describes hyperactive-impulsive children with excessive fidgeting or tapping of hands or feet or squirming in their seats. They leave their seats in classroom or other situations in which staying seated is expected. Moreover, they run or climb in situations where this behavior is inappropriate. They have difficulties in playing or engaging in hobbies quietly. On the other hand, hyperactive children tend to be in a constant motion or "on the go", or act as if they are driven by a motor. They keep on talking all the time and blurt out answers before a question has been completed asked. They tend to finish other people's sentences and speak without waiting for their turn. In order to diagnose hyperactivity and impulsivity, a child must have at least 6 of the previous symptoms of hyperactivity/impulsivity that must have persisted for at least 6 months (Association, 2000). Hyperactivity stems from deficits in the brain's executive functions which involve organization, self-monitoring and self-regulation (Barkley, 1997). Children with ADHD are not able to organize their space and time well; their desks and rooms are disorganized, and they cannot self-monitor and self-regulate their actions (Gupta, 2005). Moreover, impulsive children have a short circuit in their nerve-cell wiring, causing them to act impulsively and to have poor working memory, resulting in poor processing of incoming information (Barkley, 1997).

A European study surveyed parents of children aged 6 to 18 years old by the completion of an online questionnaire. Children were divided into two groups: ADHD group and normative population group. This study included $n=910$ parents of ADHD group and $n=995$ parents of normative population group. Compared with the normative population sample, parents reported that ADHD children consistently displayed more demanding, noisy, disruptive, disorganized and impulsive behavior in addition to an exaggerated conduct (Coghill et al., 2008).

\subsection{Pathophysiology of ADHD}

ADHD is associated with alterations in the Prefrontal cortex (PFC) and its connections to the striatum and cerebellum (Giedd, Blumenthal, Molloy, \& Castellanos, 2001). The PFC, especially the right one, plays an important role in regulating behavior and attention, and more importantly maintaining attention over a delay by inhibiting distraction (Goldman-Rakic, 1987). Lesions to the PFC will lead to distractibility, forgetfulness, impulsivity, poor planning, and locomotor hyperactivity (Itami \& Uno, 2002). A child with ADHD has impaired behavioral inhibition, increased motor activity, and inattention. All these ADHD symptoms arise from disruptions in brain circuits regulating attention and action (Aron, Robbins, \& Poldrack, 2004). The PFC is connected to several areas in the brain including sensory and motor cortices, cerebellum and basal ganglia. These structures communicate by means of catecholamine (Norepinephrine NE and Dopamine DA) secretions which enhance the regulation of behaviors and attention. Both DA and NE exhibit an inverted U influence on the PFC cognitive functions, where either too little or too much of their secretion impairs PFC function (A. F. Arnsten, 2007).

\subsubsection{Role of Norepinephrine}

Norepinephrine (NE) is a neurotransmitter that acts on three general families of adrenoceptors $\alpha 1, \alpha 2$ and $\beta 1,2$, and 3 (Mouradian, Sessler, \& Waterhouse, 1991). This neurotransmitter is secreted by locus coeruleus of the brain and targets all parts of the brain especially the PFC. NE release in the PFC improves working memory which helps in controlling behavior and attention through action at postsynaptic $\alpha 2 \mathrm{~A}$ receptors on PFC dendritic spines (A. Arnsten \& Goldman-Rakic, 1985). The latter will be activated upon binding to $\alpha 2 \mathrm{~A}$ receptors, and in turn will activate inhibitory Gi membrane protein which inhibits cAMP, closing nearby HCN channels and allowing the network to connect. However, in ADHD cases, the G protein on the postsynaptic membrane enhances cAMP production in the cytosol which opens HCN channels that are localized on the PFC dendritic spines. When HCN channels open, the postsynaptic membrane resistance lowers and inputs to the spine are shunted (M. Wang et al., 2007). Conversely, blocked $\alpha 2 \mathrm{~A}$ receptors in the PFC will impair working memory, impulse control and attention, and induce locomotor hyperactivity (C.-L. Ma, Arnsten, \& Li, 2005) (Figure 1). 


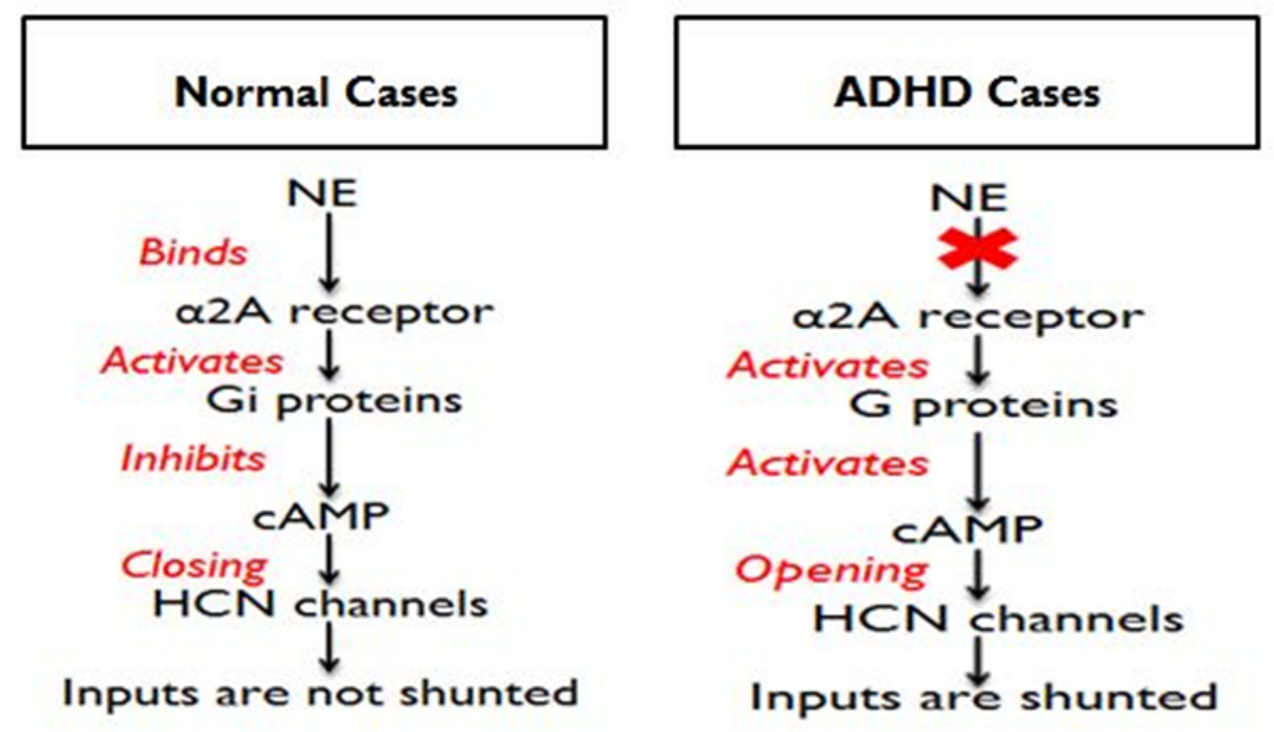

Figure 1. Norepinephrine (NE) mode of action in Normal vs. ADHD cases

\subsubsection{Role of Dopamine}

Dopamine (DA) is a neurotransmitter that acts on two families of receptors: the D1 family including D1 and D5 (Sawaguchi \& Goldman-Rakic, 1991), and the D2 family composed of D2, D3, and D4 (M. Wang, Vijayraghavan, \& Goldman-Rakic, 2004). This neurotransmitter is secreted by the substantia nigra and ventral tegmental area of the brain, and targets all parts of the brain especially the PFC. DA receptors are found in the PFC on dendritic spines (Smiley, Levey, Ciliax, \& Goldman-Rakic, 1994). Stimulation by DA enhances the working memory and the attention regulation processes of the PFC (Granon et al., 2000); nonetheless, only a modest amount of secreted DA is required to enhance behaviors, attention and working memory. Very high or very low levels of DA will impair working memory and lead to ADHD symptoms (Vijayraghavan, Wang, Birnbaum, Williams, \& Arnsten, 2007). D1/D2 receptors activated by very high or very low DA release will increase cAMP production and shunt inputs onto spines by opening HCN channels (Zahrt, Taylor, Mathew, \& Arnsten, 1997) (Figure 2). DA may also act on D4 receptors. These receptors are concentrated on GABAergic interneurons and upon stimulation they inhibit GABA transmission via Gi-mediated reduction of cAMP signaling. Weaker D4 receptor actions thus lead to excessive GABA transmission and suppression of cell firing (X. Wang, Zhong, \& Yan, 2002). In the case of ADHD, the expression of DRD4 7 repeat polymorphism allele would weaken D4 receptor efficacy and lead to insufficient D4 inhibition of GABA, and thus insufficient PFC cell firing to the other parts of the brain (Sunohara et al., 2000). 


\section{Normal Cases}

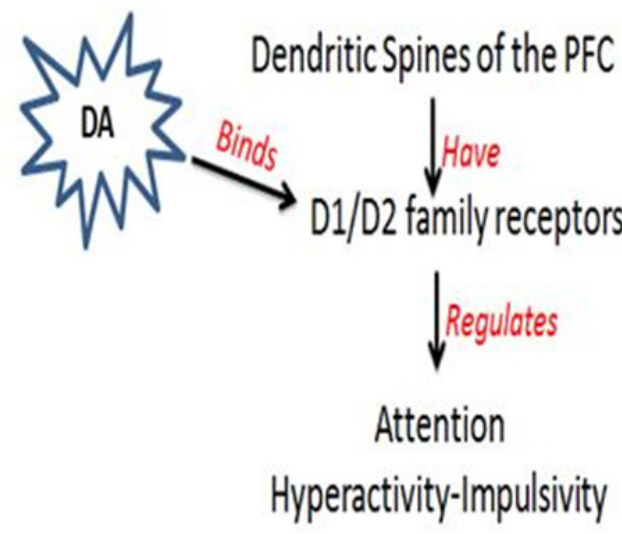

\section{ADHD Cases}

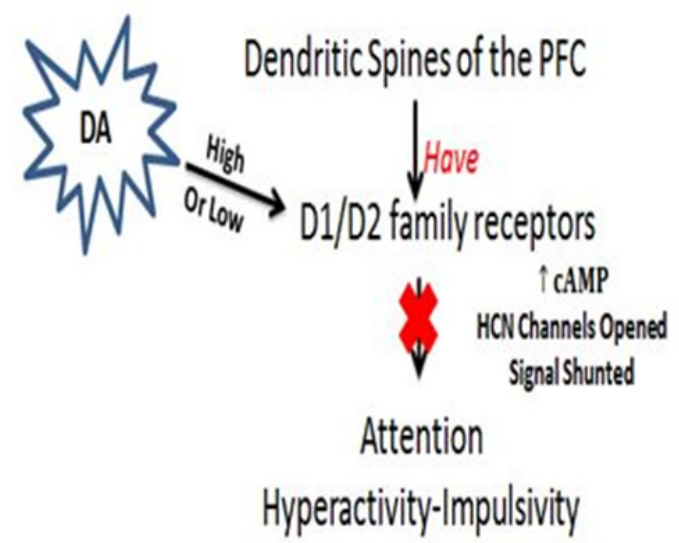

Figure 2. Dopamine (DA) mode of action in Normal vs. ADHD cases

\subsubsection{Role for the Membrane Receptor Guanylyl Cyclase-C}

DA neurons located in the midbrain ventral tegmental area and substantia nigra compacta (VTA/SNc) release DA to regulate behavioral processes such as motor activity, cognition, motivation, and learning (Emilien, Maloteaux, Geurts, Hoogenberg, \& Cragg, 1999). The membrane receptor Guanylyl Cyclase-C (GC-C) is observed to be strongly expressed throughout the VTA/SNc of the brain (Lein et al., 2007). An experiment proved that expression in the VTA/SNc in TH-GFP transgenic mice. A dual-color immunostaining revealed that GC-C stains in red, while TH (critical enzyme for DA synthesis) stains in green (Matsushita et al., 2002). VTA/SNc DA neurons appeared both red and green under the microscope after dual-color immunostaining indicating the presence of GC-C receptor on the presynaptic membrane of DA neurons (Gong et al., 2011). An activated GC-C receptor will activate Protein Kinase G (PKG) which will stimulate DA secretion to the prefrontal cortex (Figure 3A). Moreover, GC-C potentiates the excitatory responses by the mediation of glutamate and acetylcholine receptors via the activity of PKG. G and UG are ligands for GC-C, and upon binding, PKG will be activated and will potentiate the response evoked by DHPG (a ligand of glutamate receptors which excites DA neurons) (Lucas et al., 2000). An application of $\mathrm{G}$ ligand dramatically increased the firing frequency of action potentials evoked by DHPG. Moreover, GC-C KO mice were used in this experiment to study the importance of GC-C in DA neurons. In these mice, GC-C was knocked out and after addition of the ligand UG, no potentiation of the action potential was detected (Gong et al., 2011).

\subsubsection{Importance of PKG in DA secretion}

As mentioned before, upon activation of GC-C receptor, PKG will be activated and will potentiate the excitatory response of DA neurons mediated by glutamate and acetylcholine receptors (Lucas et al., 2000). To prove the importance of PKG in DA secretion, two PKG inhibitors were used: Rp-8-pCPT-cGMPs and KT5823 (Kwan, Huang, \& Yao, 2004). After activation of membrane GC-C by G ligand, no amplification in the action potential of DA neurons was detected, thus PKG is critical in the potentiation of the action potential (Gong et al., 2011). As additional proof, 8-Br-cGMP was used as a PKG activator in GC-C KO mice (Lucas et al., 2000). Upon activation by 8 -Br-cGMP, PKG amplified the action potentials evoked by DHPG (Gong et al., 2011).

\subsubsection{GC-C/PKG signaling pathway and ADHD}

Other experiments were conducted to prove that GC-C/PKG signaling pathway affects behavior by modulating brain dopamine levels. Attention and hyperactivity were both analyzed in GC-C KO mice and wild-type normal mice (Mann, Jump, $\mathrm{Wu}$, Yee, \& Giannella, 1997) by placing them in an open field to study their locomotor activity. GC-C KO mice proved to be more hyperactive when they traveled a higher distance as opposed to Wt mice. Hence, 
GC-C/PKG signaling is important in DA secretion and behavior regulation especially hyperactivity behaviors (Gong et al., 2011).

Attention was tested with an olfactory habituation test to examine whether GC-C KO mice had impaired response habituation in behaviors other than locomotion. Wt mice reduced their interest when the same odorant was presented repetitively but increased again in response to a novel odor. GC-C KO mice spent more time investigating odorant stimuli and displayed impairment in olfactory habituation after repetitive presentation of the same odorant (Gong et al., 2011). Hence, reduced response habituation in GC-C KO mice is associated with impaired attention (Zhuang et al., 2001).

To sum up, GC-C receptors found on DA neurons in VTA/SNc affect DA secretion and behavior regulations (Emilien et al., 1999). Active GC-C receptor by bound ligand (UG/G) stimulates PKG which further potentiates the excitatory responses mediated by glutamate and acetylcholine receptors (Lucas et al., 2000). Potentiation of the excitatory response means more DA neurotransmitters are being released from VTA/SNc to other parts of the brain especially to the prefrontal cortex where behaviors such as hyperactivity (Mann et al., 1997) and attention (Zhuang et al., 2001) are regulated. In ADHD cases, GC-C is knocked out, hence abnormal DA secretions render children hyperactive and inattentive (Gong et al., 2011) (Figure 3B).

\subsubsection{Role of Dopamine on Post-Synaptic Membrane}

DA neurotransmitters secreted in the PFC bind and activate D2R on the post-synaptic membrane (Smiley et al., 1994). Upon activation, the receptor will phosphorylate Akt, an intracellular signaling protein that targets mTOR (Beaulieu et al., 2004). The latter activates S6K, a transcription factor initiating transcription and translation of certain genes in the PFC, allowing the synthesis of certain proteins that play a role in neuroplasticity (Ma and Blenis 2009). Such proteins increase the connection between the PFC and other parts of the brain and thus improve attention, and reduce hyperactivity and impulsivity. However, very low or very high DA secretions in ADHD cases will prevent D2R from phosphorylating Akt. Deactivated Akt will prevent mTOR from phosphorylating S6K, and will increase the hypophosphorylated level of 4E-BP1 which is an intracellular signaling protein that blocks the synthesis of proteins responsible for neuroplasticity (Gingrich \& Caron, 1993; X. M. Ma \& Blenis, 2009). This in turn will increase cAMP production in the post-synaptic neuron and shunt inputs onto spines by opening HCN channels (Zahrt et al., 1997).
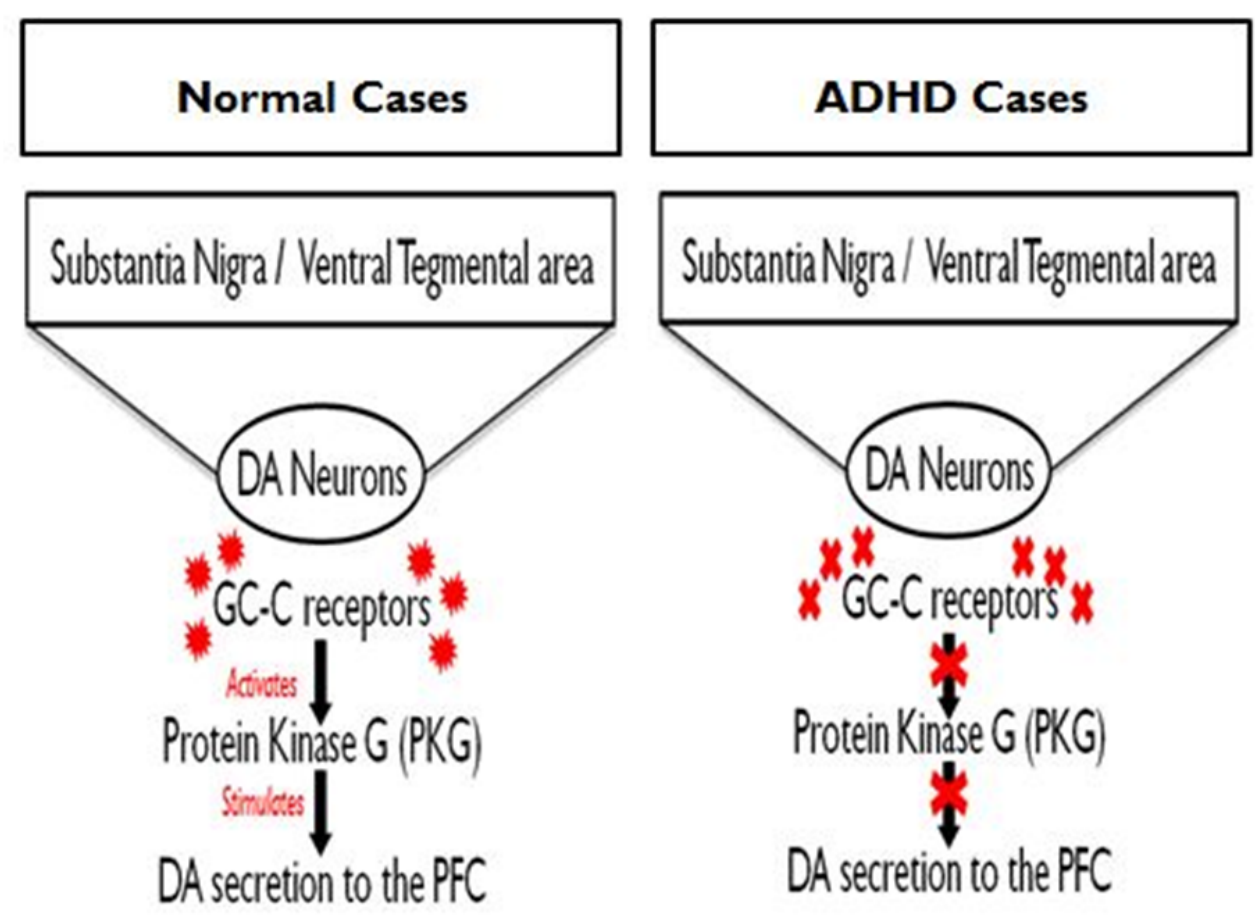

Figure 3. Role of membrane GC-C receptors in Normal cases vs. ADHD cases 


\subsection{Genetic and Environmental Causes Behind ADHD}

ADHD tends to run in families. When one family member is diagnosed with ADHD, there is a $25 \%$ to $35 \%$ chance that another will also have the condition; compared to $4 \%$ to $6 \%$ in the general public (Biederman et al., 1994). Genetic and environmental interactions can cause severe inattention, hyperactivity, or both. Researchers found that the stimulant Ritaline ${ }^{\circledR}$ (drug) calms rather than excites children with ADHD (Dyme, Sahakian, Golinko, \& Rabe, 1982). Since these drugs work by indirectly regulating dopamine levels in the brain, then dopamine secretion in the brain is one of the major causes leading to ADHD in children. Studies were done to seek out genes that affect dopamine communication and decrease its secretion in the brain such as receptor DRD4, transporter DAT, and protein SNAP-25, which help in releasing dopamine neurotransmitter from nerve cells ( $\mathrm{Li}$, Sham, Owen, \& He, 2006). DRD4 7R, a variety of the DRD4 gene associated with ADHD could affect dopamine secretion in the brain. Inheritance of this gene gave kids faster reaction times and different attention spans, which are symptoms related to the disorder (Sunohara et al., 2000). On the other hand, Susan Smalley from the University of California, Los Angeles, led the first ADHD genome scans, and found hints of ADHD genes on chromosome 5, 6, 16 and 17, and several of these gene regions overlap with those implicated in autism and dyslexia. Hence, these disorders may share neurological glitches that disrupt the brain's executive function system and the neural network that governs tasks such as problem-solving, planning, and attention (Brown, 2003).

ADHD is not only caused by genetic dysfunctions; the environment also plays an important role in inducing such a disorder in children. Studies have shown that exposing children to environmental toxicants such as prenatal cigarette smoke (Milberger, Biederman, Faraone, Chen, \& Jones, 1996), alcohol (Coles et al., 1997) and lead (Wasserman, Staghezza-Jaramillo, Shrout, Popovac, \& Graziano, 1998) put them at a higher risk for developing ADHD.

Blood lead concentrations in ADHD children and normal children in the US showed that children with blood lead concentration in the fifth quintile were at a significantly higher risk for developing ADHD (Braun, Kahn, Froehlich, Auinger, \& Lanphear, 2006).

Moreover, a significant association between prenatal environmental tobacco smoke (ETS) exposure and ADHD was found in an experiment where interactions between sex and prenatal exposure to ETS were tested. Females who were prenatally exposed to ETS were at a 4.6 fold higher risk of ADHD compared to unexposed females, whereas exposed males were at an almost significant 2 fold higher risk for ADHD than unexposed males (Braun et al., 2006).

Futhermore, prenatal exposures to tobacco smoke and alcohol cause a decrease in the cerebral as well as the cerebellum volume of ADHD cases. The effect of maternal smoking and alcohol use during pregnancy on global brain volumes in children with ADHD and normal children was studied with MRI. ADHD subjects who had been prenatally exposed to cigarettes or alcohol, unexposed ADHD subject, exposed control subjects and unexposed control subjects, were all included in the study. The MRI clearly showed that the cerebral and cerebellum volumes were the smallest in ADHD exposed children, showing that cigarette smoke and alcohol use during pregnancy decrease the volume of the brain in ADHD children and worsen the symptoms of the disorder (Mackie et al., 2007). Hence, prenatal exposure to cigarette smoke and alcohol decreases the cerebral volume especially the volume of the cerebellum grey matter in children with ADHD (De Zeeuw, Zwart, Schrama, Van Engeland, \& Durston, 2012).

\subsection{Treatments of $A D H D$}

In 1936, the U.S. Food and Drug Administration (FDA) approved that the stimulant drug Benzedrine ${ }^{\circledR}$ which contains amphetamine is an efficient in treating ADHD; young patients' behavior and performance in school improved after taking this drug (Barkley, 1981). In 1955, the FDA discovered a new psychostimulant known as Ritalin ${ }^{\circledR}$, which contains methylphenidate (Greenhill \& Osman, 2000). This drug is efficient in treating ADHD, and it is still used to treat children suffering from the disorder. These pharmacological treatments of ADHD all target catecholamine signaling in the prefrontal cortex. They can be divided as stimulants or non-stimulants. Stimulant drugs work by increasing brain chemicals such as dopamine and norepinephrine, which play essential roles in thinking, attention and other behavioral regulations (Elliott et al., 1997). However, WHO reports that stimulant drugs are not all safe and may cause side effects in ADHD children such as decreased appetite, sleep complications, personality changes, increased anxiety and irritability, stomachaches, and headaches. Hence, doctors may prescribe non-stimulant drugs when patient experience the side effects from stimulant drugs; although they take longer to start working but at the end they improve focus, attention, and impulsivity in persons with ADHD (Spencer \& Biederman, 2002). 


\subsubsection{Effect of Exercise and Methylphenidate ${ }^{\circledR}$ on ADHD}

Physical exercises could have therapeutic effects on ADHD symptoms such as hyperactivity and impulsivity (Verret, Guay, Berthiaume, Gardiner, \& Béliveau, 2012) and these effects were evident in an experiment that used two categories of rats: spontaneously hypertensive rats (SHR) and Wistar-Kyoto (WKY) rats (Sagvolden, 2000). These rats were divided into groups of four: the control group (WKY rats), the the ADHD group (SHR rats), the ADHD and exercise group (physical exercise done by SHR rats), and the fourth one was the ADHD and methylphenidate-treated group (SHR rats treated with methylphenidate ${ }^{\circledR}$ ). Rats in the exercise group were forced to run on a treadmill for 30 minutes once a day at a speed of 2 meters per minute, and rats in group 4 were treated with methylphenidate ${ }^{\circledR}$ which is a stimulant drug that enhances the secretion of catecholamine neurotransmitters (Kim et al., 2011). All four groups were tested for their hyperactivity in an open-field arena (Open-field test) which is a large white square inside which rats are placed (Cho, Baek, \& Baek, 2014). Results showed that ADHD rats were more hypertensive than control rats. Consequently, hyperactivity was measured again after finishing their physical exercise (group 3) and after treating rats in group 4 by placing all rats in the open-field arena (3 times). A change in hyperactivity was detected the most in the exercising rats and treated rats (Archer \& Kostrzewa, 2012); every time they were placed in the open-field arena, their hyperactivity decreased. Thus, both exercise and methylphenidate ${ }^{\circledR}$ are efficient in reducing hyperactivity behaviors in ADHD cases (Cho et al., 2014).

Physical exercises do not only regulate hypertensive behaviors, but also impulsivity in ADHD rats. All four groups of rats were placed on an elevated plus maze consisting of 2 open arms and 2 closed arms. Normally, once placed on the elevated maze, non-impulsive rats would go directly towards the closed arms and away from the open arms to avoid falling over. The latency time measured in this experiment represents the latency of staying in the open arm in the elevated plus maze task. Results showed that exercising and treatment with methylphenidate ${ }^{\circledR}$ were both efficient in decreasing impulsivity in ADHD rats since they passed less time in the open arm compared to untreated ADHD rats. ADHD group demonstrated a significant increase in the latency time and the number of entrances into the open arm, as compared with the control group (Cho et al., 2014).

At the neurological level of ADHD cases, the activated D2-like receptor decreases the excitability of DA neurons and its release (Wu, Xiao, Sun, Zou, \& Zhu, 2012). This receptor is expressed on the presynaptic and postsynaptic neurons of the subtantia nigra, and plays an important role in the regulation of DA neuronal activity, synthesis, release and uptake (Negyessy \& Goldman Rakic, 2005). However, physical activity stimulates dopamine release in the central nerve system and suppresses the expression of D2-like receptor in the subtantia nigra (O'dell et al., 2007). After ADHD rats were allowed to run on a treadmill for 30 minutes (Cho et al., 2014), hyperactivity in rats was suppressed and their DA levels increased (Ji, Kim, Park, \& Bahn, 2014). Thus, treadmill exercise suppresses hyperactivity and D2 receptor expression in ADHD rats and enhances the secretion of DA neurotransmitter which alleviates hyperactivity, impulsivity, and controls attention, movement, cognition, mood and reward (Negyessy \& Goldman Rakic, 2005). Hence, physical exercise might be of great value in the treatment of ADHD in children, along with the use of drugs such as methylphenidate ${ }^{\circledR}$ (Cho et al., 2014).

\subsubsection{SK609: another treatment for ADHD}

Low doses of methylphenidate ${ }^{\circledR}$ increase DA and NE levels in the PFC leading to cognitive enhancement (C. Berridge et al., 2006; Rowley et al., 2014). Recently, SK609 was designed as a D3R agonist, and characterized for its effects on monoamine transporters (Nakajima et al., 2013; Sokoloff, Giros, Martres, Bouthenet, \& Schwartz, 1990). Results demonstrate that SK609, in addition to its D3R agonist effects, plays the role of NE transporters' (NET) substrate and blocks its action in the uptake of NE (Marshall et al., 2019). To validate SK609 effects on catecholamine secretion in the PFC, DA and NE efflux levels were measured using microdialysis assays. A peak dose of SK609 (4 mg/kg) significantly increased both DA and NE levels in the PFC (Marshall et al., 2019). From here, SK609's actions on DA and NE secretion raise the question about its effect on PFC-mediated cognitive tasks. Thus, the molecule was tested for its effect on attention in low performing rats (Marshall et al., 2019). Results showed that SK609 significantly improved performance in a dose-dependent manner with peak effects at $4 \mathrm{mg} / \mathrm{kg}$. Further, SK609 produced an inverted-U shaped dose response, similar to that of methylphenidate ${ }^{\circledR}$ (C. W. Berridge et al., 2012). Specifically, 6 of the 7 low performing rats significantly improved in performance when treated with SK609 by responding correctly to a task, thereby transitioning into high performers (Marshall et al., 2019). Moreover, SK609's peak effect was blocked by a pre-treatment with either the D2/D3R antagonist 'raclopride' $(0.05 \mathrm{mg} / \mathrm{kg})$ or the alpha-1 adrenergic receptor antagonist 'prazosin' $(0.25 \mathrm{mg} / \mathrm{kg})$. Both D2/D3R antagonists impaired sustained attention performance in rats, confirming a role for both DA and NE in promoting sustained attention (Bari \& Robbins, 2013; Hillhouse \& Prus, 2013; Puumala, Riekkinen SR, \& Sirviö, 1997; Shoaib \& Bizarro, 2005). On the other hand, NET inhibitors 'desipramine' and 'atomoxetine' were used, leading to 
an elevation in DA levels in addition to NE in the PFC, suggesting that prefrontal NET plays a role in the uptake of both DA and NE (Carboni, Tanda, Frau, \& Chiara, 1990; Higashino et al., 2014). Usually, methylphenidate ${ }^{\circledR}$ blocks NET and DAT: it improves attention, but as a side effect also increases locomotor activity by increasing the extracellular DA level in the PFC (Rowley et al., 2014). However, SK609 (2, 4, and $8 \mathrm{mg} / \mathrm{kg}$ ) did not induce spontaneous locomotor activity in an open field task, proving that SK609 lacks inhibitory effects on DAT (Marshall et al., 2019). Studies suggest SK609 may be better suited for treating attention deficit than other psychostimulants like methylphenidate ${ }^{\circledR}$. In conclusion, SK609 is a novel D3R agonist with selective inhibitory effects at NET. It penetrates the brain and increases DA and NE levels in the PFC. This increase in extracellular catecholamine concentrations is responsible for the significant improvement of attention. The peak effect of SK609 was similar to the improvement observed with methylphenidate ${ }^{\circledR}$. Most importantly, SK609 has a low affinity for DAT, as it did not trigger hyperlocomotion in rats. These unique properties of SK609 differentiate it from existing therapies for ADHD, many of which are misused for their cognitive and performance-enhancing properties.

\section{Discussion}

Nowadays, heated debates around the ADHD controversy, questioning the disorder as being real or incorrectly diagnosed and thus "fraudulent". After being classified as a psychiatric disorder in the DSM, ADHD cannot be dismissed as a complete myth. However, ADHD is currently receiving the "fraud" reputation following misdiagnosis/overdiagosis/overtreatment by doctors and parents. Every misbehaving child is sent to visit a pediatrician, who claims: "It's ADHD, here's methylphenidate ${ }^{\circledR}$ ". Thus, children are wrongly diagnosed with ADHD every time they demonstrate an "active" behavior while $90 \%$ of these 4.5 million kids do not have any abnormal DA metabolism or biological basis (Kagan, 2009). This exponential increase in methylphenidate ${ }^{\circledR}$ prescriptions in recent years has worried researchers about its misuse among individuals who do not meet the full diagnostic criteria for ADHD such as young children and students in search of cognitive improvement (Schmitz, Chao, \& Wyse, 2019). Hence, the answer for "ADHD: a disorder?" would be YES only when health professionals diagnose their patients correctly and ethically. Similarly, the answer for "ADHD a fraud?" would also be YES in the case where doctors and parents diagnose their misbehaving children as having ADHD, without even thinking of the main reasons behind these abnormal behaviors (Figure 4). Fatigue (insufficient catecholamines) or stress (excessive catecholamine) may produce changes in attention and behavioral regulation that resemble ADHD symptoms. This may be problematic in children exposed to stressors such as families experiencing divorce, illness, or death, or social stressors at school. Every child is at risk of being exposed to such stressors leading to attention problems and behavioral deregulations, but it does not imply that this child suffers from ADHD (Brennan \& Arnsten, 2008). In addition to that, $53 \%$ of children in the US are being diagnosed as having ADHD and are being treated pharmaceutically; a significant number when compared to the $0.5 \%$ of children diagnosed as having ADHD in France. The main cause behind that difference is that health professionals and parents in the US misdiagnose children as suffering from ADHD by prescribing drugs to treat them instead of searching for the real psychological causes behind their abnormal behavior. However, in France, psychiatrists treat misbehaving children by looking to the underlying issues causing the misbehavior: they search for the causes behind the child's misbehavior before prescribing any drug (Molland, 2013).

To show the effect of methylphenidate ${ }^{\circledR}$ on misdiagnosed children, studies have shown that this drug influences protein kinase B-mammalian target of rapamycin complex 1 signaling pathways (Akt-mTOR). PC12 cells, a cell line derived from a pheochromocytoma of the rat adrenal medulla, have been widely used as an in vitro experimental model to study ADHD (Grünblatt, Bartl, Marinova, \& Walitza, 2013). These cells are also used to study the effects of methylphenidate ${ }^{\circledR}$ (Bartl et al., 2010; Grünblatt et al., 2013), since it is a dopaminergic neuronal cell that can synthesize, store, secrete, and take up DA (Pan, Zhu, Hwu, \& Jankovic, 2012). Based on that, the PC12 cells' response to methylphenidate ${ }^{\circledR}$ treatment was studied by analyzing Akt-mTOR pathway, as well as the mTOR substrates, 4E-BP1 and S6K kinase (Schmitz et al., 2019). Results show that short term methylphenidate ${ }^{\circledR}$ treatment decreased phosphorylated Akt, mTOR, and S6K ratio in PC12 cells. On the other hand, long term treatment increased phosphorylated Akt and mTOR ratio. Moreover, phosphorylation levels of 4E-BP1 were decreased at 15 and $30 \mathrm{~min}$ (short term treatment) and increased at 1 and $6 \mathrm{~h}$ (long term treatment). These findings prove that methylphenidate ${ }^{\circledR}$ alters cell signaling in $\mathrm{PC} 12$ cells and its responses differ according to the time of exposure to this psychostimulant (Schmitz et al., 2019).

As mentioned before, methylphenidate ${ }^{\circledR}$ increases DA levels in various brain regions through DAT blocking (Reinoso, Undie, \& Levitt, 1996; Todd, 1992). Activation of D2R by excess dopamine secretion inhibits Akt by dephosphorylating its regulatory threonine 308 residue (Beaulieu et al., 2004). Akt phosphorylation in PC12 cells

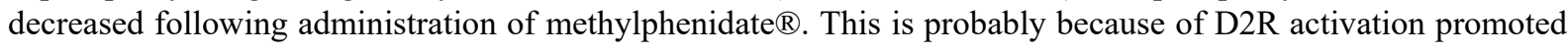


by a further increase in DA levels triggered by methylphenidate ${ }^{\circledR}$ treatment in a short term treatment. However, phosphorylated Akt level was increased after a long methylphenidate ${ }^{\circledR}$ treatment $(1 \mathrm{~h})$ in PC12 cells (Schmitz et al., 2019); most likely due to an increase in the extracellular DA metabolites DOPAC and HVA levels which break DA after methylphenidate ${ }^{\circledR}$ treatment (Bartl et al., 2010). Based on this, it was deduced that the decrease in Akt phosphorylation in the first minutes followed by its increase in PC12 cells after long term methylphenidate ${ }^{\circledR}$ treatment, may be associated with increased DA levels and D2R activation in the first place, followed by its increased degradation decrease and the eventual D2R inactivation (Schmitz et al., 2019).

Furthermore, mTOR kinase is targeted by D2R/Akt pathway that plays important roles in neuronal functions, including control of synaptic plasticity, long term potentiation, axonal growth, and regeneration (Lin \& Holt, 2008; Richter \& Klann, 2009; Willis \& Twiss, 2006). These processes require protein synthesis, which can be potentially regulated by the mTOR substrates: S6K and 4E-BPs (X. M. Ma \& Blenis, 2009). S6K is activated upon phosphorylation by mTOR and stimulates translation elongation. Whereas 4E-BP1 selectively represses cap-dependent translation and is inhibited by mTOR (Gingrich \& Caron, 1993; X. M. Ma \& Blenis, 2009). Results show that methylphenidate ${ }^{\circledR}$ decreases phosphorylated mTOR ratio, as well as phosphorylation of S6K in PC12 cells after a short term treatment. Moreover 4E-BP1 hyperphosphorylated levels were decreased, whereas 4E-BP1 hypophosphorylated levels increased in PC12 cells after a short term treatment (Schmitz et al., 2019). Hence, the decreased Akt phosphorylation observed after short treatment with methylphenidate ${ }^{\circledR}$, as well as the decreased phosphorylation of mTOR induced translation impairment, affecting processes which require protein synthesis as synaptic plasticity, axonal growth, and regeneration. On the other hand, after a long methylphenidate ${ }^{\circledR}$ treatment, phosphorylated Akt leads to mTOR activation. Upon activation, 4E-BP1 hyperphosphorylated levels increase and protein synthesis is activated (Schmitz et al., 2019) leading to an increase in branching, spine number (Bowling et al., 2014) and morphological complexity (Benes, Paskevich, \& Domesick, 1983; Meredith et al., 2000; Navari \& Dazzan, 2009).

Summing up, Akt-mTOR pathway in PC12 cells, as well as other important pathways involved in translation, protein synthesis, cell growth, survival, proliferation, neurogenesis, and neuroplasticity respond to methylphenidate ${ }^{\circledR}$ according to exposure duration (Schmitz et al., 2019).

A drug such as methylphenidate ${ }^{\circledR}$ is widely misused by children and adolescents who do not meet the full diagnostic criteria for ADHD (Akay et al., 2006; Dafny \& Yang, 2006; Gonçalves, Baptista, \& Silva, 2014; Loureiro-Vieira, Costa, de Lourdes Bastos, Carvalho, \& Capela, 2017). 90\% of these 4.5 million kids do not have an abnormal DA metabolism (Kagan, 2009). Taking psychostimulants like methylphenidate ${ }^{\circledR}$ would enhance the secretion of DA in the PFC (Reinoso et al., 1996; Todd, 1992), but its Excess will activate D2R which will dephosphorylate Akt (Beaulieu et al., 2004). The latter is deactivated and will prevent mTOR from phosphorylating S6K. Deactivated S6K will cause hypophosphorylated 4E-BP1 ratio to increase, preventing the synthesis of some proteins responsible for neuroplasticity, an essential mechanism allowing the PFC to connect with other parts of the brain in order to propagate catecholamine signals that control attention, hyperactivity and impulsivity (Lin \& Holt, 2008; Richter \& Klann, 2009; Willis \& Twiss, 2006). After a long treatment with methylphenidate ${ }^{\circledR}$, DA metabolites levels will increase in the PFC and will destroy all the available dopamine (Bartl et al., 2010). This will allow methylphenidate ${ }^{\circledR}$ to bind to D2R, which will phosphorylate and activate Akt, which in turn will phosphorylate mTOR inducing the activation of S6K and the blockage of 4E-BP1 by phosphorylation. Hence, long term treatment with methylphenidate ${ }^{\circledR}$ will allow the synthesis of proteins responsible for neuroplasticity (Schmitz et al., 2019). In these cases, ADHD is considered a hoax because parents and health professionals think that methylphenidate ${ }^{\circledR}$ is the only solution to adjust attention problems in misbehaving children: the drug will only show efficacy after long term treatment and will eventually solve attention-related problems; but the unfortunate hidden part is that their normal DA levels in the PFC is getting destroyed by metabolites.

\section{Conclusion}

All ADHD symptoms do not occur without a reason. This disorder is caused by many dysfunctions in the brain especially the prefrontal cortex area: the site of attention regulation, hyperactivity regulation and working memory improvement. ADHD children are inattentive, impulsive and sometimes hyperactive, and this is due to a decline in the cerebral volume, a decrease in the connectivity between several parts of the brain and the prefrontal cortex, and most importantly to an abnormal secretion of DA and NE in the PFC. All these biological factors are enough to understand the reasons behind ADHD symptoms and to classify it as a legitimate disorder. Children may be also exposed to environmental factors worsening ADHD symptoms. Lead, prenatal alcohol and tobacco exposure are all environmental toxicants making children more inattentive, hyperactive and impulsive. As for the treatments, 
drug treatments for ADHD are efficient, but not as important as psychotherapy: parents and peers should get an education on how to treat ADHD children in a way to reduce their symptoms. In conclusion, ADHD is a psychiatric disorder, but its legitimacy was doubted when physicians began to over-diagnose and over-treat children by giving them drugs without looking to the underlying causes behind their abnormal behavior. A longer period of assessment and observation may decrease the odds of a misdiagnosis. During this period, the child should be encouraged to have a healthier lifestyle including a regular physical activity and a balanced diet containing less processed food and refined sugars. Nevertheless, more research using a single-subject design approach is needed to rule out biological versus environmental origins of ADHD type symptoms.

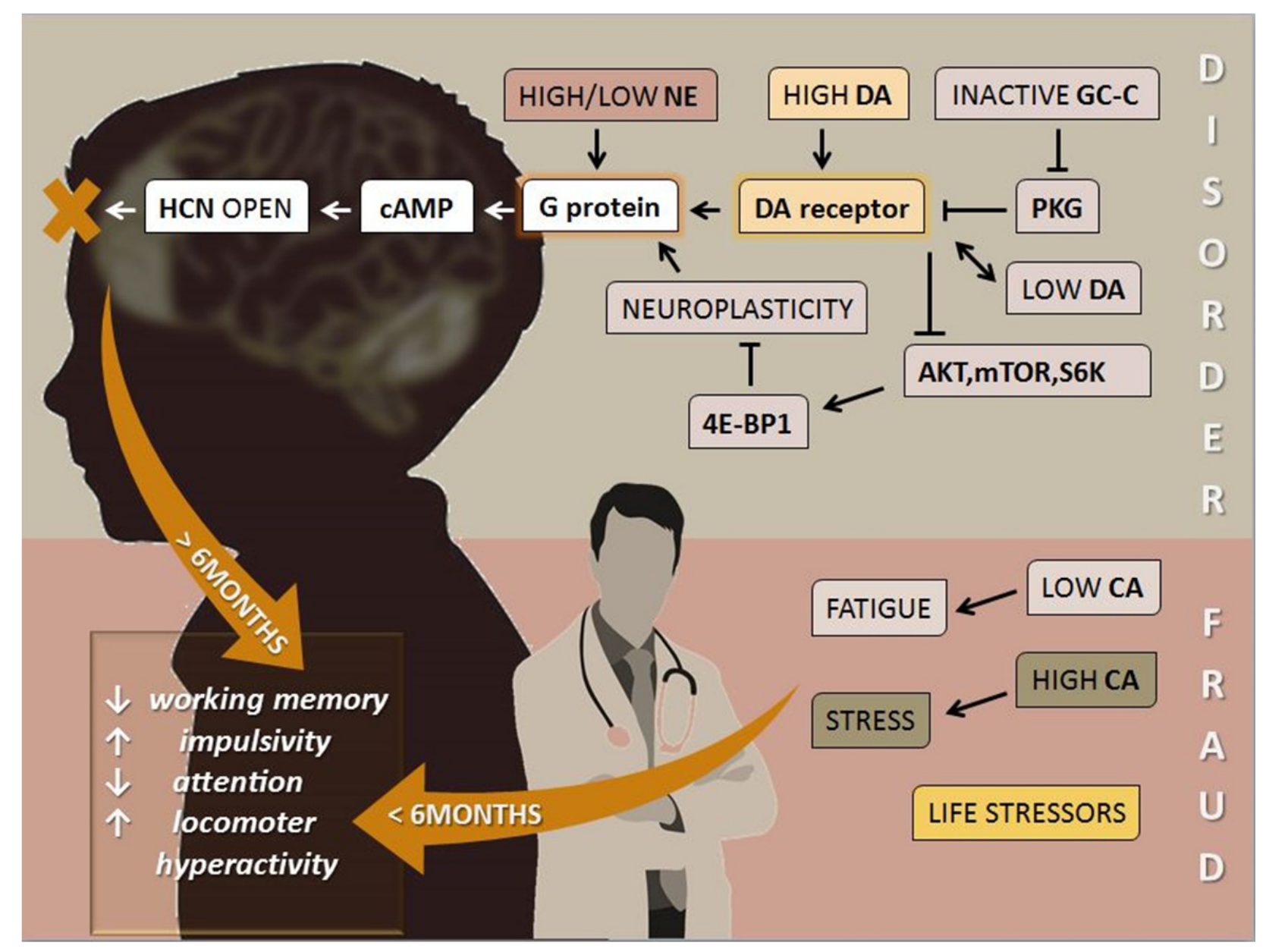

Figure 4. Summative diagram showing ADHD caused by biological dysfunctions ("Disorder" panel) or as misdiagnosed when caused by life stressors ("Fraud" panel)

\section{Competing Interests Statement}

The authors declare that there are no competing or potential conflicts of interest.

\section{References}

Akay, A. P., Kaya, G. Ç., Emiroğlu, N. İ., Aydın, A., Monkul, E. S., Taşçı, C., Miral, S., \& Durak, H. (2006). Effects of long-term methylphenidate treatment: A pilot follow-up clinical and SPECT study. Progress in Neuro-Psychopharmacology and Biological Psychiatry, 30(7), 1219-1224. https://doi.org/10.1016/j.pnpbp.2006.02.014

Archer, T., \& Kostrzewa, R. M. (2012). Physical exercise alleviates ADHD symptoms: regional deficits and development trajectory. Neurotoxicity research, 21(2), 195-209. https://doi.org/10.1007/s12640-011-9260-0

Arnsten, A., \& Goldman-Rakic, P. S. (1985). Alpha 2-adrenergic mechanisms in prefrontal cortex associated with 
cognitive decline in aged nonhuman primates. Science, 230(4731), 1273-1276. https://doi.org/10.1126/science.2999977

Arnsten, A. F. (2007). Catecholamine and second messenger influences on prefrontal cortical networks of "representational knowledge": a rational bridge between genetics and the symptoms of mental illness. Cerebral cortex, 17(suppl_1), i6-i15. https://doi.org/10.1093/cercor/bhm033

Aron, A. R., Robbins, T. W., \& Poldrack, R. A. (2004). Inhibition and the right inferior frontal cortex. Trends in cognitive sciences, 8(4), 170-177. https://doi.org/10.1016/j.tics.2004.02.010

Association, A. P. (1952). Diagnostic and Statistical Manual of Mental Disorders I (1st ed.). Washington, D.C: American Psychiatric Association Press. https://doi.org/10.1093/jama/9780195176339.022.529

Association, A. P. (1968). Diagnostic and Statistical Manual of Mental Disorders II (2nd ed.). Washington, D.C: American Psychiatric Association Press. https://doi.org/10.1093/jama/9780195176339.022.529

Association, A. P. (1980). Diagnostic and statistical manual of mental disorders; DSM-III. Washington DC. https://doi.org/10.1093/jama/9780195176339.022.529

Association, A. P. (2000). Diagnostic and Statistical Manual of Mental Disorders IV (4th ed.). Washington, D.C: American Psychiatric Association Press. https://doi.org/10.1093/jama/9780195176339.022.529

Association, A. P. (2013). Diagnostic and Statistical Manual of Mental Disorders V. (5th ed.). Washington, D.C: American Psychiatric Association Press;. https://doi.org/10.1093/jama/9780195176339.022.529

Bari, A., \& Robbins, T. (2013). Noradrenergic versus dopaminergic modulation of impulsivity, attention and monitoring behaviour in rats performing the stop-signal task. Psychopharmacology, 230(1), 89-111. https://doi.org/10.1007/s00213-013-3141-6

Barkley, R. A. (1981). Hyperactive children: A handbook for diagnosis and treatment. Guilford press New York. https://doi.org/10.1016/0005-7967(83)90066-9

Barkley, R. A. (1997). Behavioral inhibition, sustained attention, and executive functions: constructing a unifying theory of ADHD. Psychological bulletin, 121(1), 65. https://doi.org/10.1037//0033-2909.121.1.65

Bartl, J., Link, P., Schlosser, C., Gerlach, M., Schmitt, A., Walitza, S., Riederer, P., \& Grünblatt, E. (2010). Effects of methylphenidate: the cellular point of view. ADHD Attention Deficit and Hyperactivity Disorders, 2(4), 225-232. https://doi.org/10.1007/s12402-010-0039-6

Beaulieu, J.-M., Sotnikova, T. D., Yao, W.-D., Kockeritz, L., Woodgett, J. R., Gainetdinov, R. R., \& Caron, M. G. (2004). Lithium antagonizes dopamine-dependent behaviors mediated by an AKT/glycogen synthase kinase 3 signaling cascade. Proceedings of the National Academy of Sciences, 101(14), 5099-5104. https://doi.org/10.1073/pnas.0307921101

Benes, F. M., Paskevich, P. A., \& Domesick, V. B. (1983). Haloperidol-induced plasticity of axon terminals in rat substantia nigra. Science, 221(4614), 969-971. https://doi.org/10.1126/science.6879197

Berridge, C., Devilbiss, D., Andrzejewski, M., Arnsten, A., Kelley, A., \& Schmeichel, B. (2006). Methylphenidate preferentially increases catecholamine neurotransmission within the prefrontal cortex at low doses that enhance cognitive function. Biol Psychiatry, 60, 1111-1120.

Berridge, C. W., Shumsky, J. S., Andrzejewski, M. E., McGaughy, J. A., Spencer, R. C., Devilbiss, D. M., \& Waterhouse, B. D. (2012). Differential sensitivity to psychostimulants across prefrontal cognitive tasks: differential involvement of noradrenergic $\alpha 1$-and $\alpha 2$-receptors. Biological psychiatry, 71(5), 467-473. https://doi.org/10.1016/j.biopsych.2011.07.022

Biederman, J. (1998). Attention-deficit/hyperactivity disorder: a life-span perspective. The Journal of clinical psychiatry, 59, 4-16.

Biederman, J., Faraone, S. V., Spencer, T., Wilens, T., Mick, E., \& Lapey, K. A. (1994). Gender differences in a sample of adults with attention deficit hyperactivity disorder. Psychiatry research, 53(1), 13-29. https://doi.org/10.1016/0165-1781(94)90092-2

Bowling, H., Zhang, G., Bhattacharya, A., Pérez-Cuesta, L. M., Deinhardt, K., Hoeffer, C. A., ... Chao, M. V. (2014). Antipsychotics activate mTORC1-dependent translation to enhance neuronal morphological complexity. Sci. Signal., 7(308), ra4-ra4. https://doi.org/10.1126/scisignal.2004331

Braun, J. M., Kahn, R. S., Froehlich, T., Auinger, P., \& Lanphear, B. P. (2006). Exposures to environmental toxicants and attention deficit hyperactivity disorder in US children. Environmental health perspectives, 
114(12), 1904. https://doi.org/10.1289/ehp.9478

Brennan, A. R., \& Arnsten, A. F. (2008). Neuronal mechanisms underlying attention deficit hyperactivity disorder: the influence of arousal on prefrontal cortical function. Annals of the New York Academy of Sciences, 1129(1), 236-245. https://doi.org/10.1196/annals.1417.007

Brown, K. (2003). New attention to ADHD genes: researchers are trying to tease apart the genetic and environmental contributions to childhood's most common mental disorder.(Neuroscience). Science, 301(5630), 160-162. https://doi.org/10.1126/science.301.5630.160

Carboni, E., Tanda, G., Frau, R., \& Chiara, G. D. (1990). Blockade of the noradrenaline carrier increases extracellular dopamine concentrations in the prefrontal cortex: evidence that dopamine is taken up in vivo by noradrenergic terminals. Journal of neurochemistry, 55(3), 1067-1070. https://doi.org/10.1111/j.1471-4159.1990.tb04599.x

Cho, H. S., Baek, D. J., \& Baek, S. S. (2014). Effect of exercise on hyperactivity, impulsivity and dopamine D2 receptor expression in the substantia nigra and striatum of spontaneous hypertensive rats. Journal of exercise nutrition \& biochemistry, 18(4), 379. https://doi.org/10.5717/jenb.2014.18.4.379

Coghill, D., Soutullo, C., d'Aubuisson, C., Preuss, U., Lindback, T., Silverberg, M., \& Buitelaar, J. (2008). Impact of attention-deficit/hyperactivity disorder on the patient and family: results from a European survey. Child and Adolescent Psychiatry and Mental Health, 2(1), 31. https://doi.org/10.1186/1753-2000-2-31

Coles, C. D., Platzman, K. A., Raskind-Hood, C. L., Brown, R. T., Falek, A., \& Smith, I. E. (1997). A comparison of children affected by prenatal alcohol exposure and attention deficit, hyperactivity disorder. Alcoholism: Clinical and Experimental Research, 21(1), 150-161. https://doi.org/10.1111/j.1530-0277.1997.tb03743.x

Dafny, N., \& Yang, P. B. (2006). The role of age, genotype, sex, and route of acute and chronic administration of methylphenidate: a review of its locomotor effects. Brain research bulletin, 68(6), 393-405. https://doi.org/10.1016/j.brainresbull.2005.10.005

De Zeeuw, P., Zwart, F., Schrama, R., Van Engeland, H., \& Durston, S. (2012). Prenatal exposure to cigarette smoke or alcohol and cerebellum volume in attention-deficit/hyperactivity disorder and typical development. Translational psychiatry, 2(3), e84. https://doi.org/10.1038/tp.2012.12

Dyme, I. Z., Sahakian, B. J., Golinko, B. E., \& Rabe, E. F. (1982). Perseveration induced by methylphenidate in children: preliminary findings. Progress in neuro-psychopharmacology \& biological psychiatry. https://doi.org/10.1016/s0278-5846(82)80177-2

Elliott, R., Sahakian, B. J., Matthews, K., Bannerjea, A., Rimmer, J., \& Robbins, T. W. (1997). Effects of methylphenidate on spatial working memory and planning in healthy young adults. Psychopharmacology, 131(2), 196-206. https://doi.org/10.1007/s002130050284

Emilien, G., Maloteaux, J.-M., Geurts, M., Hoogenberg, K., \& Cragg, S. (1999). Dopamine receptors - physiological understanding to therapeutic intervention potential. Pharmacology \& therapeutics, 84(2), 133-156. https://doi.org/10.1016/s0163-7258(99)00029-7

Gaub, M., \& Carlson, C. L. (1997). Gender differences in ADHD: a meta-analysis and critical review. Journal of the American Academy of Child \& Adolescent Psychiatry, 36(8), 1036-1045. https://doi.org/10.1097/00004583-199708000-00011

Giedd, J. N., Blumenthal, J., Molloy, E., \& Castellanos, F. X. (2001). Brain imaging of attention deficit/hyperactivity disorder. Annals of the New York Academy of Sciences, 931(1), 33-49. https://doi.org/10.1111/j.1749-6632.2001.tb05772.x

Gingrich, J. A., \& Caron, M. G. (1993). Recent advances in the molecular biology of dopamine receptors. Annual review of neuroscience, 16(1), 299-321. https://doi.org/10.1146/annurev.ne.16.030193.001503

Goldman-Rakic. (1987). Circuitry of the primate prefrontal cortex and the regulation of behavior by representational memory. . American Physiological Society(1987), p. 373-417.

Gonçalves, J., Baptista, S., \& Silva, A. P. (2014). Psychostimulants and brain dysfunction: a review of the relevant neurotoxic effects. Neuropharmacology, 87, 135-149. https://doi.org/10.1016/j.neuropharm.2014.01.006

Gong, R., Ding, C., Hu, J., Lu, Y., Liu, F., Mann, E., Xu, F., Cohen, M. B., \& Luo, M. (2011). Role for the membrane receptor guanylyl cyclase-C in attention deficiency and hyperactive behavior. Science, 333(6049), 1642-1646. https://doi.org/10.1126/science.1207675 
Granon, S., Passetti, F., Thomas, K. L., Dalley, J. W., Everitt, B. J., \& Robbins, T. W. (2000). Enhanced and impaired attentional performance after infusion of D1 dopaminergic receptor agents into rat prefrontal cortex. Journal of neuroscience, 20(3), 1208-1215. https://doi.org/10.1523/jneurosci.20-03-01208.2000

Greenhill, L. L., \& Osman, B. B. (2000). Ritalin: Theory and practice. Mary Ann Liebert.

Grünblatt, E., Bartl, J., Marinova, Z., \& Walitza, S. (2013). In vitro study methodologies to investigate genetic aspects and effects of drugs used in attention-deficit hyperactivity disorder. Journal of Neural Transmission, 120(1), 131-139. https://doi.org/10.1007/s00702-012-0869-9

Gupta. (2005). Attention Deficit/Hyperactivity Disorder Is a Serious Problem for Many Children. Opposing Viewpoints in Context.

Higashino, K., Ago, Y., Umehara, M., Kita, Y., Fujita, K., Takuma, K., \& Matsuda, T. (2014). Effects of acute and chronic administration of venlafaxine and desipramine on extracellular monoamine levels in the mouse prefrontal cortex and striatum. European journal of pharmacology, 729, 86-93. https://doi.org/10.1016/j.ejphar.2014.02.012

Hillhouse, T. M., \& Prus, A. J. (2013). Effects of the neurotensin NTS1 receptor agonist PD149163 on visual signal detection in rats. European journal of pharmacology, 721(1-3), 201-207. https://doi.org/10.1016/j.ejphar.2013.09.035

Itami, S., \& Uno, H. (2002). Orbitofrontal cortex dysfunction in attention-deficit hyperactivity disorder revealed by reversal and extinction tasks. Neuroreport, 13(18), 2453-2457. https://doi.org/10.1097/00001756-200212200-00016

Ji, E.-S., Kim, C.-J., Park, J. H., \& Bahn, G. H. (2014). Duration-dependence of the effect of treadmill exercise on hyperactivity in attention deficit hyperactivity disorder rats. Journal of exercise rehabilitation, $10(2), 75$. https://doi.org/10.12965/jer.140107

Kagan. (2009). The Man Who “Discovered” ADHD Makes a Startling Deathbed Confession.

Kim, H., Heo, H.-I., Kim, D.-H., Ko, I.-G., Lee, S.-S., Kim, S.-E., .. \& \& Kim, J.-D. (2011). Treadmill exercise and methylphenidate ameliorate symptoms of attention deficit/hyperactivity disorder through enhancing dopamine synthesis and brain-derived neurotrophic factor expression in spontaneous hypertensive rats. Neuroscience letters, 504(1), 35-39. https://doi.org/10.1016/j.neulet.2011.08.052

Kwan, H.-Y., Huang, Y., \& Yao, X. (2004). Regulation of canonical transient receptor potential isoform 3 (TRPC3) channel by protein kinase G. Proceedings of the National Academy of Sciences, 101(8), 2625-2630. https://doi.org/10.1073/pnas.0304471101

Lein, E. S., Hawrylycz, M. J., Ao, N., Ayres, M., Bensinger, A., Bernard, A.,... Byrnes, E. J. (2007). Genome-wide atlas of gene expression in the adult mouse brain. Nature, 445(7124), 168.

Li, D., Sham, P. C., Owen, M. J., \& He, L. (2006). Meta-analysis shows significant association between dopamine system genes and attention deficit hyperactivity disorder (ADHD). Human molecular genetics, 15(14), 2276-2284. https://doi.org/10.1093/hmg/dd1152

Lin, A. C., \& Holt, C. E. (2008). Function and regulation of local axonal translation. Current opinion in neurobiology, 18(1), 60-68. https://doi.org/10.1016/j.conb.2008.05.004

Loureiro-Vieira, S., Costa, V. M., de Lourdes Bastos, M., Carvalho, F., \& Capela, J. P. (2017). Methylphenidate effects in the young brain: friend or foe? International Journal of Developmental Neuroscience, 60, 34-47. https://doi.org/10.1016/j.ijdevneu.2017.04.002

Lucas, K. A., Pitari, G. M., Kazerounian, S., Ruiz-Stewart, I., Park, J., Schulz, S., ... \& Waldman, S. A. (2000). Guanylyl cyclases and signaling by cyclic GMP. Pharmacological reviews, 52(3), 375-414.

Ma, C.-L., Arnsten, A. F., \& Li, B.-M. (2005). Locomotor hyperactivity induced by blockade of prefrontal cortical $\alpha 2$-adrenoceptors in monkeys. Biological psychiatry, https://doi.org/10.1016/j.biopsych.2004.11.004

Ma, X. M., \& Blenis, J. (2009). Molecular mechanisms of mTOR-mediated translational control. Nature reviews Molecular cell biology, 10(5), 307. https://doi.org/10.1038/nrm2672

Mackie, S., Shaw, P., Lenroot, R., Pierson, R., Greenstein, D. K., Nugent III, B., ... Rapoport, J. L. (2007). Cerebellar development and clinical outcome in attention deficit hyperactivity disorder. American Journal of Psychiatry, 164(4), 647-655. https://doi.org/10.1176/appi.ajp.164.4.647 
Mann, E. A., Jump, M. L., Wu, J., Yee, E., \& Giannella, R. A. (1997). Mice lacking the guanylyl cyclase C receptor are resistant to STa-induced intestinal secretion. Biochemical and biophysical research communications, 239(2), 463-466. https://doi.org/10.1006/bbrc.1997.7487

Marshall, C. A., Brodnik, Z. D., Mortensen, O. V., Reith, M. E., Shumsky, J. S., Waterhouse, B. D., España, R. A., \& Kortagere, S. (2019). Selective activation of Dopamine D3 receptors and norepinephrine transporter blockade enhance sustained attention. Neuropharmacology.

Matsushita, N., Okada, H., Yasoshima, Y., Takahashi, K., Kiuchi, K., \& Kobayashi, K. (2002). Dynamics of tyrosine hydroxylase promoter activity during midbrain dopaminergic neuron development. Journal of neurochemistry, 82(2), 295-304. https://doi.org/10.1046/j.1471-4159.2002.00972.x

Meredith, G. E., De Souza, I. E., Hyde, T. M., Tipper, G., Wong, M. L., \& Egan, M. F. (2000). Persistent alterations in dendrites, spines, and dynorphinergic synapses in the nucleus accumbens shell of rats with neuroleptic-induced dyskinesias. Journal of Neuroscience, 20(20), 7798-7806. https://doi.org/10.1523/jneurosci.20-20-07798.2000

Milberger, S., Biederman, J., Faraone, S. V., Chen, L., \& Jones, J. (1996). Is maternal smoking during pregnancy a risk factor for attention deficit hyperactivity disorder in children? The American journal of psychiatry, 153(9), 1138. https://doi.org/10.1176/ajp.153.9.1138

Molland, J. (2013). Why are ADHD rates 20 times higher in the US than in France?.

Mouradian, R. D., Sessler, F. M., \& Waterhouse, B. D. (1991). Noradrenergic potentiation of excitatory transmitter action in cerebrocortical slices: evidence for mediation by an $\alpha 1$ receptor-linked second messenger pathway. Brain research, 546(1), 83-95. https://doi.org/10.1016/0006-8993(91)91162-t

Nakajima, S., Gerretsen, P., Takeuchi, H., Caravaggio, F., Chow, T., Le Foll, B., Mulsant, B., Pollock, B., \& Graff-Guerrero, A. (2013). The potential role of dopamine D3 receptor neurotransmission in cognition. European Neuropsychopharmacology, 23(8), 799-813. https://doi.org/10.1016/j.euroneuro.2013.05.006

Navari, S., \& Dazzan, P. (2009). Do antipsychotic drugs affect brain structure? A systematic and critical review of MRI findings. Psychological medicine, 39(11), 1763-1777. https://doi.org/10.1017/s0033291709005315

Negyessy, L., \& Goldman Rakic, P. S. (2005). Subcellular localization of the dopamine D2 receptor and coexistence with the calcium-binding protein neuronal calcium sensor-1 in the primate prefrontal cortex. Journal of Comparative Neurology, 488(4), 464-475. https://doi.org/10.1002/cne.20601

O’dell, S., Gross, N., Fricks, A., Casiano, B., Nguyen, T., \& Marshall, J. (2007). Running wheel exercise enhances recovery from nigrostriatal dopamine injury without inducing neuroprotection. Neuroscience, 144(3), 1141-1151. https://doi.org/10.1016/j.neuroscience.2006.10.042

Pan, T., Zhu, J., Hwu, W.-J., \& Jankovic, J. (2012). The role of alpha-synuclein in melanin synthesis in melanoma and dopaminergic neuronal cells. PloS one, 7(9), e45183. https://doi.org/10.1371/journal.pone.0045183

Pediatrics, A. A. O. (2000). Clinical practice guidelines: diagnosis and evaluation of the child with $\begin{array}{llll}\text { attention-deficity/hyperactivity } \quad \text { disorder. } & \text { Pediatrics, } & \text { 105(2000), }\end{array}$ https://doi.org/10.1542/peds.105.5.1158

Pena, J., \& Montiel-Nava, C. (2003). The attention deficit hyperactivity disorder myth or reality? Revista de neurologia, 36(2), 173-179. https://doi.org/10.33588/rn.3602.2002161

Puumala, T., Riekkinen SR, P., \& Sirviö, J. (1997). Modulation of vigilance and behavioral activation by alpha-1 adrenoceptors in the rat. Pharmacology Biochemistry and Behavior, 56(4), 705-712.

Reinoso, B., Undie, A., \& Levitt, P. (1996). Dopamine receptors mediate differential morphological effects on cerebral cortical neurons in vitro. Journal of neuroscience research, 43(4), 439-453. https://doi.org/10.1002/(sici)1097-4547(19960215)43:4\%3C439::aid-jnr5\%3E3.0.co;2-g

Richter, J. D., \& Klann, E. (2009). Making synaptic plasticity and memory last: mechanisms of translational regulation. Genes \& development, 23(1), 1-11. https://doi.org/10.1101/gad.1735809

Rowley, H. L., Kulkarni, R. S., Gosden, J., Brammer, R. J., Hackett, D., \& Heal, D. J. (2014). Differences in the neurochemical and behavioural profiles of lisdexamfetamine methylphenidate and modafinil revealed by simultaneous dual-probe microdialysis and locomotor activity measurements in freely-moving rats. Journal of psychopharmacology, 28(3), 254-269. https://doi.org/10.1177/0269881113513850

Sagvolden, T. (2000). Behavioral validation of the spontaneously hypertensive rat (SHR) as an animal model of 
attention-deficit/hyperactivity disorder (AD/HD). Neuroscience \& Biobehavioral Reviews, 24(1), 31-39. https://doi.org/10.1016/s0149-7634(99)00058-5

Sawaguchi, T., \& Goldman-Rakic, P. S. (1991). D1 dopamine receptors in prefrontal cortex: involvement in working memory. Science, 251(4996), 947-950. https://doi.org/10.1126/science.1825731

Schmitz, F., Chao, M. V., \& Wyse, A. T. (2019). Methylphenidate alters Akt-mTOR signaling in rat pheochromocytoma cells. International Journal of Developmental Neuroscience, 73, 10-18. https://doi.org/10.1016/j.ijdevneu.2018.12.004

Sharma, A., \& Couture, J. (2014). A review of the pathophysiology, etiology, and treatment of attention-deficit hyperactivity disorder (ADHD). Annals of Pharmacotherapy, 48(2), 209-225. https://doi.org/10.1177/1060028013510699

Shoaib, M., \& Bizarro, L. (2005). Deficits in a sustained attention task following nicotine withdrawal in rats. Psychopharmacology, 178(2-3), 211-222. https://doi.org/10.1007/s00213-004-2004-6

Smiley, J. F., Levey, A.I., Ciliax, B. J., \& Goldman-Rakic, P. S. (1994). D1 dopamine receptor immunoreactivity in human and monkey cerebral cortex: predominant and extrasynaptic localization in dendritic spines. Proceedings of the National Academy of Sciences, 91(12), 5720-5724. https://doi.org/10.1073/pnas.91.12.5720

Sokoloff, P., Giros, B., Martres, M.-P., Bouthenet, M.-L., \& Schwartz, J.-C. (1990). Molecular cloning and characterization of a novel dopamine receptor (D3) as a target for neuroleptics. Nature, 347(6289), 146. https://doi.org/10.1038/347146a0

Spencer, T., \& Biederman, J. (2002). Non-stimulant treatment for attention-deficit/hyperactivity disorder. Journal of Attention Disorders, 6(1_suppl), 109-119. https://doi.org/10.1177/070674370200601s13

Still, G. F. (1902). Some abnormal psychical conditions in children. Lancet.

Sunohara, G. A., Roberts, W., Malone, M., Schachar, R. J., Tannock, R., Basile, V. S., ... Moriarty, J. (2000). Linkage of the dopamine D4 receptor gene and attention-deficit/hyperactivity disorder. Journal of the American Academy of Child \& Adolescent Psychiatry, 39(12), 1537-1542. https://doi.org/10.1097/00004583-200012000-00017

Todd, R. D. (1992). Neural development is regulated by classical neurotransmitters: dopamine D2 receptor stimulation enhances neurite outgrowth. Biological psychiatry, 31(8), 794-807. https://doi.org/10.1016/0006-3223(92)90311-m

Verret, C., Guay, M.-C., Berthiaume, C., Gardiner, P., \& Béliveau, L. (2012). A physical activity program improves behavior and cognitive functions in children with ADHD: an exploratory study. Journal of attention disorders, 16(1), 71-80. https://doi.org/10.1177/1087054710379735

Vijayraghavan, S., Wang, M., Birnbaum, S. G., Williams, G. V., \& Arnsten, A. F. (2007). Inverted-U dopamine D1 receptor actions on prefrontal neurons engaged in working memory. Nature neuroscience, 10(3), 376. https://doi.org/10.1038/nn1846

Wang, M., Ramos, B. P., Paspalas, C. D., Shu, Y., Simen, A., Duque, A., Vijayraghavan, S., Brennan, A., Dudley, A., \& Nou, E. (2007). $\alpha 2$ A-adrenoceptors strengthen working memory networks by inhibiting cAMP-HCN channel signaling in prefrontal cortex. Cell, 129(2), 397-410. https://doi.org/10.1016/j.cell.2007.03.015

Wang, M., Vijayraghavan, S., \& Goldman-Rakic, P. S. (2004). Selective D2 receptor actions on the functional circuitry of working memory. Science, 303(5659), 853-856. https://doi.org/10.1126/science.1091162

Wang, X., Zhong, P., \& Yan, Z. (2002). Dopamine D4 receptors modulate GABAergic signaling in pyramidal neurons of prefrontal cortex. Journal of Neuroscience, 22(21), 9185-9193. https://doi.org/10.1523/jneurosci.22-21-09185.2002

Wasserman, G. A., Staghezza-Jaramillo, B., Shrout, P., Popovac, D., \& Graziano, J. (1998). The effect of lead exposure on behavior problems in preschool children. American Journal of Public Health, 88(3), 481-486. https://doi.org/10.2105/ajph.88.3.481

Willis, D. E., \& Twiss, J. L. (2006). The evolving roles of axonally synthesized proteins in regeneration. Current opinion in neurobiology, 16(1), 111-118. https://doi.org/10.1016/j.conb.2006.01.002

Wu, J., Xiao, H., Sun, H., Zou, L., \& Zhu, L.-Q. (2012). Role of dopamine receptors in ADHD: a systematic meta-analysis. Molecular neurobiology, 45(3), 605-620. https://doi.org/10.1007/s12035-012-8278-5 
Zahrt, J., Taylor, J. R., Mathew, R. G., \& Arnsten, A. F. (1997). Supranormal stimulation of D1 dopamine receptors in the rodent prefrontal cortex impairs spatial working memory performance. Journal of neuroscience, 17(21), 8528-8535. https://doi.org/10.1523/jneurosci.17-21-08528.1997

Zhuang, X., Oosting, R. S., Jones, S. R., Gainetdinov, R. R., Miller, G. W., Caron, M. G., \& Hen, R. (2001). Hyperactivity and impaired response habituation in hyperdopaminergic mice. Proceedings of the National Academy of Sciences, 98(4), 1982-1987. https://doi.org/10.1073/pnas.98.4.1982

\section{Copyrights}

Copyright for this article is retained by the author(s), with first publication rights granted to the journal.

This is an open-access article distributed under the terms and conditions of the Creative Commons Attribution license (http://creativecommons.org/licenses/by/4.0/). 